\title{
Devolver a história, materializar o trauma: Observações sobre os corpos migrantes em Cavalo Dinheiro (2014) e Vitalina Varela (2019) de Pedro Costa
}

\author{
Catarina Andrade \\ Universidade Federal de Pernambuco \\ catarina.oandrade@ufpe.br \\ https://orcid.org/0000-0002-2547-7118
}

\section{Mariana Cunha}

Programa de Pós-graduação em Comunicação da Universidade Federal de Pernambuco, PNPD/CAPES maccunha@gmail.com

https://orcid.org/0000-0003-1202-1194

RESUM O Este artigo propõe uma reflexão sobre a forma como Cavalo Dinheiro (2014) e Vitalina Varela (2019), do realizador português Pedro Costa, restauram o direito de narrar e materializam os efeitos do trauma relacionados à migração e ao colonialismo, a partir de uma análise da inscrição dos corpos e subjetividades diaspóricas no espaço pós-colonial contemporâneo, mais especificamente no contexto da representação de imigrantes e descendentes de imigrantes cabo-verdianos em Portugal. Tomamos a noção de materialidade como prisma para esta análise, tanto no sentido da materialidade do aparato cinematográfico empregado pelo realizador, quanto no sentido da materialidade da própria imagem e suas operações formais na construção da experiência da história e do trauma. Argumentamos que essas operações formais, especialmente o uso da temporalidade (histórica e fílmica) e do enquadramento que criam um distanciamento, não só revelam uma estética própria como também um engajamento político e ético do cinema de Pedro Costa.

PALAVRAS-CHA VE Pedro Costa; trauma; corpo; materialidade; história; afeto.

"Chegaste atrasada", escuta Vitalina ao desembarcar em Portugal. No aeroporto, ao descer as escadas do avião, aparecem os pés descalços de Vitalina, molhados de urina. É dessa forma que irrompe na tela a personagem que nomeia Vitalina Varela (2019), filme mais recente de Pedro Costa. Um grupo de mulheres, funcionárias da limpeza do aeroporto, está à espera, no pátio do aeroporto, para recebê-la. Uma 
delas abraça Vitalina, cujo semblante não vemos, e afirma, também em voz baixa, que o marido havia sido enterrado há três dias. Aconselha, ainda, que volte para sua terra. Nessa primeira aparição de Vitalina no filme, duas preocupações se revelam: uma delas está relacionada a uma ideia de pertencimento, de casa e de geografia, dilaceradas pela experiência do deslocamento e da migração; a outra diz respeito às temporalidades dissonantes reveladas nas falas dessas personagens, das suas histórias atravessadas pela suspensão do tempo. Essa suspensão nos remete diretamente ao filme anterior do realizador português, Cavalo Dinheiro (2014), e à longa cena em que seu personagem principal, Ventura, está num elevador, suspenso no tempo e no espaço, e na qual se desenrola um longo diálogo entre Ventura e um soldado do golpe antirrevolucionário do 11 de março de 1975.

A ideia de suspensão geográfica e histórica nos leva a indagar como os corpos migrantes rompem certas linearidades espaciais e temporais. Assim, a partir de um olhar para as múltiplas espacialidades e temporalidades - geografias e histórias - que atravessam Cavalo Dinheiro e Vitalina Varela, este artigo propõe uma reflexão sobre a forma como os filmes restauram um direito de narrar e como os efeitos do trauma vinculado à migração e ao colonialismo são postos em cena nos filmes. A análise toma como ponto de partida a inscrição dos corpos e subjetividades diaspóricas no espaço pós-colonial contemporâneo, mais especificamente no contexto da representação de imigrantes e descendentes de imigrantes cabo-verdianos em Portugal, recorrente no cinema de Pedro Costa. Tomamos a noção de materialidade como prisma para esta análise, tanto no sentido da materialidade do aparato cinematográfico empregado pelo realizador, quanto no sentido da materialidade da própria imagem e suas operações formais na construção da experiência do trauma.

\section{Devolver a história}

Cavalo Dinheiro e Vitalina Varela são filmes cujos personagens, temporalidades, espaços e temas se cruzam de diversas maneiras. Não se trata, no entanto, de uma continuação narrativa entre um e outro. Enquanto Cavalo Dinheiro encena as memórias e a doença de Ventura, e suas deambulações por hospitais, fábricas, ruas vazias e corredores subterrâneos, Vitalina Varela narra a chegada de Vitalina a Portugal e seu luto. 
Como se sabe, a colaboração artística entre Pedro Costa e Ventura (José Tavares Borges) já se concretizava em Juventude em Marcha (2006), do qual Ventura é protagonista. Como enfatiza Nuno Barradas Jorge $(2020,4)$, desde o final dos anos 1990, o processo de criação do cineasta apoia-se fortemente na colaboração com atores não profissionais que reaparecem em mais de um filme e constroem suas histórias a partir da "posição intersticial entre o documental e o ficcional", tecendo, assim, continuidades, rupturas e cruzamentos entre os filmes. De maneira semelhante, a história de Vitalina já havia sido anunciada em Cavalo Dinheiro. Vitalina aparece no filme de 2014 e narra em detalhe como recebeu a notícia da morte do marido quando ainda estava em Cabo Verde, e sua viagem até Portugal. Lê, em sussurros, certidões de nascimento, casamento e óbito. As narrativas de Ventura e Vitalina em Cavalo Dinheiro são fragmentadas, o que torna o filme um cuidadoso estudo sobre os corpos exauridos pela doença, pelo luto e por seus traumas. Já Ventura ressurge em Vitalina Varela, mas desta vez como padre. A narrativa de Vitalina Varela, por sua vez, tem uma linearidade mais nítida. Como escreveu Jacques Rancière sobre sua estrutura narrativa:

Clássica, inclusive hollywoodiana: começa com homens voltando de um funeral. Em seguida, o avião que traz a mulher que amava ao defunto. Ela conhecerá testemunhas da vida dele, procurará sua casa e descobrirá seus segredos. Pouco a pouco, o quebra-cabeça da vida de ambos, do que os uniu e os separou, será reconstruído. E a viagem através do tempo termina com a evocação de um jovem casal feliz, construindo uma casa onde jamais viveram juntos, mas cuja imagem os unirá para sempre. Uma história de amor infeliz, mas mesmo assim indestrutível. (Rancière 2020, nossa tradução)

Apesar do retorno a uma estrutura narrativa mais linear e, talvez, uma fuga do que havia sido proposto em Cavalo Dinheiro, em que a fragmentação e a mescla de temporalidades são refletidas na desdramatização mais intensa das performances, uma observação dos atravessamentos estéticos nesses dois filmes revela um esforço para devolver a história individual de sujeitos que foram desterritorializados e muitas vezes silenciados. Porém, trata-se de devolver uma forma de narrar que passa ao largo do testemunho único do trauma. Este ato de devolução de uma forma de narrar tomou forma pelo gesto de abandono do aparato cinematográfico pesado de $35 \mathrm{~mm}$ por parte do 
diretor Pedro Costa, que deu lugar a uma nova materialidade a partir do filme No Quarto da Vanda (2000):

O filme [No Quarto da Vanda] foi feito depois de Ossos (1997) e representa uma mudança radical: em vez de câmeras $35 \mathrm{~mm}$, refletores, uma grande equipe e caminhões, Pedro Costa escolheu uma nova forma de trabalhar. Por dois anos seguidos, foi diariamente ao bairro das Fontaínhas e, munido de uma pequena câmera digital, fez um filme que questiona toda a maquinaria utilizada na indústria cinematográfica atual. O novo método veio para substituir a desproporção entre o esforço empregado em uma grande produção e o seu resultado, que não conseguia apreender a beleza que o realizador via no bairro e na vida de seus habitantes. (Duarte 2010,11)

A adaptação a um novo aparato incide também na forma de filmar. Para Daniel Ribeiro Duarte $(2010,11)$, essa mudança evidencia uma "respeitosa distância" que o realizador estabelece com os sujeitos que filma, assim como os espaços que habitam, ao passo que o registro testemunha ainda as transformações desses espaços - no caso a destruição do bairro das Fontaínhas. Nuno Barradas Jorge (2020, 2) também enfatiza a centralidade da "materialidade do processo de produção" na estética dos filmes de Costa, cuja prática artística se caracteriza pelo uso câmera de vídeo digital e na relação de co-criação estabelecida com suas personagens. Como, então, essa mudança na materialidade do aparato transforma a forma de filmar e, consequentemente, a forma de narrar? Ao se colocar no lugar de observação de sujeitos diaspóricos, da história do colonialismo e suas consequências no tempo e espaço pós-colonial, o cinema de Pedro Costa não apela a uma narrativa simbólica que reconstrói, com pretensão de tornar palpável, uma história desses corpos migrantes, deixados à margem da História. Os corpos em cena, silenciados, traumatizados, insurgem como testemunhas da opressão no presente, mas que se relacionam com o passado e com o futuro de maneira não linear ou cronológica. Nesses espaços da ruína, esses corpos migrantes estão no lugar do não pertencimento e da marginalização.

É possível afirmar que o cinema de Pedro Costa restaura um "direito de narrar" (Bhabha 2003, 197) a esses corpos silenciados, a partir da construção estética de uma experiência histórica na qual a câmera filma o movimento dentro de uma certa impassibilidade dos planos e quase ausência de ação dramática, mas que capta cuidadosamente os gestos e expressões desses corpos desterritorializados e traumatizados. Bhabha 
entende o direito de narrar a partir de sua leitura da obra $A$ Condição Humana (1958), de Hannah Arendt. Para o autor, esse direito não indicaria apenas uma prerrogativa legal, mas "é também uma questão de forma estética e ética", que está relacionado à liberdade e com o lugar de onde se fala (Bhabha 2003, 197). Posteriormente, Bhabha afirma que "o direito de narrar, se quiserem, é um direito enunciativo o direito dialógico de falar e ser falado, de significar e ser interpretado, de falar e ser ouvido, de acenar e saber que receberá uma atenção respeitosa" (Bhabha 2014, nossa tradução).

Assim, a maneira que Pedro Costa escolhe para narrar a história privilegia a atenção à materialidade dos corpos. Ele busca, na imobilidade espaço-temporal dos corpos e da própria imagem, a restituição de uma narrativa ainda a tempo de ser contada e de um tempo em suspensão. Os corpos silenciados de Ventura e Vitalina não parecem representar algo; ao contrário, eles se tornam "presenças" em cena, promovendo uma experiência corporal com o filme. Nesse sentido, os filmes refletem também uma escolha ética e estética ao restaurar a história desses personagens. A ideia de suspensão ecoa a afirmação de Walter Benjamin no ensaio "Sobre o Conceito de História" (1940), em que diz que "pensar não inclui apenas o movimento de ideias, mas também sua imobilização" (Benjamin 1994, 231). Em Pedro Costa, vemos um cinema que não inclui apenas as imagens em movimentos, mas explora os efeitos de sua imobilidade.

A partir dessa imobilidade, torna visível aquilo que é impossível de ser representado, a vida "de mortos-vivos", como descreveu Rancière (2012, 162), ou, para usar um termo de Didi-Huberman, dos "figurantes" da história. Ao discorrer sobre os figurantes no cinema, Didi-Huberman faz referência às mulheres e aos homens que funcionam como parergon, ou seja, emoldurando a ação que se desenrola na dimensão narrativa de um filme. Esse grupo de pessoas pode ser caracterizado como “'homens sem qualidades' de uma encenação", correspondendo, antes de mais nada, na economia cinematográfica, a um acessório de humanidade" (Didi-Huberman 2017, 22-23). Contudo, é possível afirmar que o que é considerado acessório é trazido para o centro, deixando de funcionar como moldura. Pedro Costa transforma esses corpos desterritorializados e “atrasados”, em protagonistas, porém em presenças no deslocamento.

Tomamos a noção de figurante empregada por Didi-Huberman para entender a encenação tanto dos protagonistas quanto dos personagens 
secundários em Cavalo Dinheiro e Vitalina Varela, porque, apesar da centralidade de Ventura e Vitalina nas narrativas, o esvaziamento da ação dramática e a performance desdramatizada de todos os personagens ao mesmo tempo realçam as histórias comuns entre eles. Seus personagens são sentidos como uma presença, figurantes de suas histórias. De muitos não sabemos os nomes, não sabemos exatamente de onde vêm, pois o filme não nos introduz a eles de forma pedagógica, linear. Nesse sentido, Pedro Costa coloca essas presenças em cena e restaura, como já dito anteriormente, este "direito de narrar", devolve a esses corpos narrativas possíveis, restaura suas histórias. Sua câmera é paciente, não exatamente imóvel. De fato, ela espera que o espectador possa apreender, a partir da observação desses corpos, a história que foi ocultada, silenciada. Além disso, oscilando entre visibilidade e invisibilidade pelo chiaroscuro operado pelo realizador e diretor de fotografia, Leonardo Simões, esses corpos figurantes se convertem em testemunhas silenciosas, desses "espaços sem lugares, tempo sem duração" (Bhabha 1998, 202), que é o espaço estático desses que habitam as bordas de uma "realidade intervalar" (Bhabha 1998, 35), consequência do colonialismo.

Cavalo Dinheiro começa aproximando as periferias de Nova Iorque e Lisboa ao exibir uma sequência de fotografias de trabalhadores norteamericanos produzidas pelo jornalista e fotógrafo americanodinamarquês Jacob Riis, ligado aos movimentos sociais americanos do final do século XIX. São fotografias de grupos de pessoas em lugares fechados, que dão um ar claustrofóbico às imagens. Outras retratam os casebres empobrecidos, com roupas penduradas em varais. Em seguida, a obra Retrato de Negro (1822-1823), do pintor francês Théodore Géricault (1791-1824) que, simpático ao movimento abolicionista, dedicou os últimos dois anos de sua vida a produzir inúmeros retratos de negros, no desejo de criar uma grande tela a partir desses rostos para revelar e denunciar o tráfico negreiro. Os olhos do negro de Géricault possuem um mesmo gesto expressivo que os olhos de Ventura e Vitalina. Para além da correlação estética entre os diferentes tipos de imagens, Nuno Barradas Jorge (2020) propõe uma análise da natureza intertextual na construção de Cavalo Dinheiro. Frisamos que, para este autor, o processo de colaboração anterior ao filme, iniciado em Juventude em Marcha, entre Costa e Ventura foi o que tornou possível a realização de Cavalo Dinheiro, que faz um minucioso trabalho a partir das memórias de Ventura. Assim, o processo criativo de Costa é fundamentalmente intertextual e manifesta-se nas referências a outros 
filmes, às fotografias de Riis e à pintura de Géricault, aos documentos pessoais de Vitalina lidos por ela, e ao "interlúdio musical" com a música Alto Cutelo do grupo cabo-verdiano "Os Tubarões" (Jorge 2020, 129). Nesse sentido, a perspectiva intertextual proposta por Jorge nos leva a pensar a dimensão histórica das fontes documentais articuladas no filme, que estão, a todo momento, a tensionar as dimensões estética e política.

A imobilidade, própria à arte fotográfica, é recuperada pelo cinema de Costa que coloca sob tensão os planos de pouca ação dramática pela expressividade dos olhares; desses olhares em close-up que olham para e através da câmera, que se mesclam em presente, passado e futuro de uma mesma história.
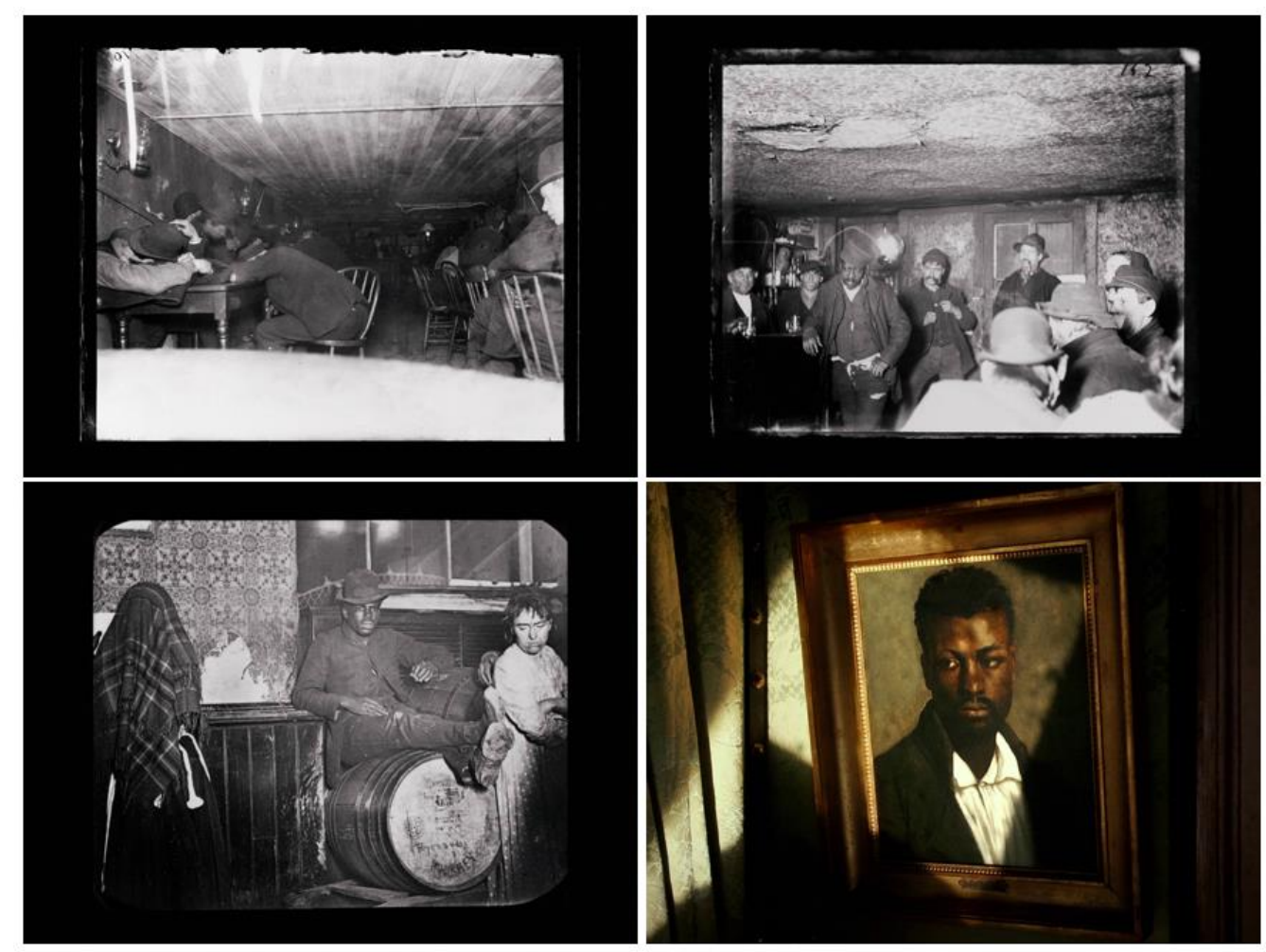

Imagens 1, 23 e 4: Fotografias de Jacob Riis e pintura de Théodore Géricault em Cavalo Dinheiro | ( ) OPTEC Sociedade Óptica Técnica.

Como escreveu Jacques Rancière sobre a política nos filmes de Pedro Costa,

seus filmes têm como tema essencial uma situação que esteja no cerne dos atuais desafios políticos: o destino dos explorados, dos que vieram de longe, das antigas colônias africanas, para trabalhar nos canteiros de obras portugueses; dos que perderam a família, a saúde, por vezes a vida, nesses 
canteiros de obras; dos que se amontoaram nos casebres dos subúrbios antes de serem mandados para moradias novas, mais claras, mais modernas e nem por isso mais habitáveis. (Rancière 2012, 147)

Nota-se, nas fotografias que figuram no início de Cavalo Dinheiro, um impulso didático e um desejo de relacionar histórias distantes no tempo e no espaço. As fotografias são apresentadas em série, como um slide show, de forma extradiegética. Já a pintura de Géricault entra no espaço diegético do filme, numa moldura pendurada em alguma parede. Emoldurado no quadro e enquadrado pela câmera, o personagem de Géricault nos introduz aos espaços escuros e subterrâneos de Cavalo Dinheiro, cuja câmera se desloca do negro da pintura para os corredores sem luz, num dos raros movimentos de câmera no filme. No entanto, como coloca Rancière $(2012,148)$, a câmera de Pedro Costa "nunca faz o trajeto habitual que desloca a objetiva dos lugares da miséria para aqueles onde os dominantes a produzem ou a geram”. Nesses filmes, não se sente uma linearidade narrativa que aponte para as causas e consequências da miséria vivida pelos personagens. De forma mais evidente em Cavalo Dinheiro, Pedro Costa converte esses corpos em sujeitos de suas próprias histórias.

Além do uso das fotografias e da pintura no início do filme, há também, em Cavalo Dinheiro, um uso enigmático de imagens de estátuas, que são, em sua maioria, monumentos espalhados pela cidade. Em algum momento, por exemplo, Ventura senta na cadeira de uma sala escura e encara uma máscara africana pendurada na parede. Em vários outros momentos, imagens de estátuas expostas em monumentos da cidade são enquadradas, como na sequência da leitura que Vitalina faz das certidões. Ao mesmo tempo em que percebemos uma inquietação em relação aos heróis da história, com aqueles que foram monumentalizados e eternizados, essas imagens operam também no registro da imobilidade que os filmes de Pedro Costa problematizam.

A estética da imobilidade também é tensionada nas imagens dos personagens. É nesse registro que Pedro Costa os monumentaliza. Esses corpos desterritorializados, imigrantes ou descendentes de imigrantes cabo-verdianos em Portugal, raramente se tornam visíveis em sua integralidade. Por meio de jogos pictóricos de luz e sombra, Costa deixa uma parte à sombra. Como comenta Ventura em Vitalina Varela, "Era uma noite imensa, partind o o mundo em dois. Aquela metade era a que ficara envolta em sombra. E dessa sombra nós somos feitos" (01:53:01 
-01:53:20). Nessa fala de Ventura, podemos entender esse mundo bipartido como a fissura de que fala Rancière $(2012,163)$, que divide a experiência em compartilhável e incompartilhável, assim como a fissura da história que não é de todo revelada. Além disso, a sombra a que se refere Ventura pode ser entendida uma metáfora dos figurantes, assessórios de humanidade, que estão sempre à sombra dos "verdadeiros" heróis da História. Uma vida à sombra é uma vida sombria.

Em Cavalo Dinheiro, fatos históricos são articulados de maneira fragmentada às falas de Ventura. Acometido por uma doença “dos nervos", Ventura é examinado por um médico, que o entrevista sem aparecer na tela. Pergunta, como se para se certificar da lucidez de Ventura: “Em que estação do ano é que estamos?”, e Ventura responde: "Estamos na primavera." Depois, "Que dia é hoje?”; "11 de março de 1975." E, finalmente, "Quem é o Presidente da República?”; "Parece que é o General António de Spínola.” (00:12:15-00:12:48). A referência explícita à Revolução dos Cravos e à data de 11 de março de 1975 (data da tentativa de golpe), ${ }^{1}$ evoca a busca para relacionar a participação de imigrantes na Revolução dos Cravos e ao mesmo tempo seu contínuo esquecimento e marginalização dentro deste momento político. A intensidade da opressão histórica se faz sentir na cena em que Ventura caminha quase nu (apenas levando um chapéu, cueca e botas) e é seguindo por um tanque de guerra e parado por dois soldados que lhe apontam uma arma. É importante salientar, mais uma vez, os entrecruzamentos das narrativas de Ventura, cuja experiência traumática após a Revolução de 25 de abril já havia sido apresentada em Juventude em Marcha. Ao discutir o processo de co-criação entre Pedro Costa e Ventura para Cavalo Dinheiro, Nuno Barradas Jorge descreve uma construção narrativa em cima das memórias de Ventura, que evidencia o paciente trabalho de criação conjunta entre o diretor e seus personagens colaboradores:

Este trabalho em torno das memórias de Ventura veio a compor uma narrativa em que diferentes compreensões de tempo - cronológico e subjetivo, vivido ou imaginado - ligam histórias individuais a momentos históricos e contextos

\footnotetext{
${ }^{1}$ É importante pontuar que o 11 de março de 1975, liderado pelo general António de Spínola, símbolo do setor mais à direita de Portugal, foi um golpe antirrevolucionário falhado, uma vez que ao acelerar o processo revolucionário em curso no país, o golpe teve uma consequência contrária aos seus objetivos.
} 
políticos particulares. Neste sentido (...), Cavalo Dinheiro pode ser entendido como um desenvolvimento de uma narrativa pessoal iniciada em Juventude em Marcha. (Jorge 2020, 132, nossa tradução)
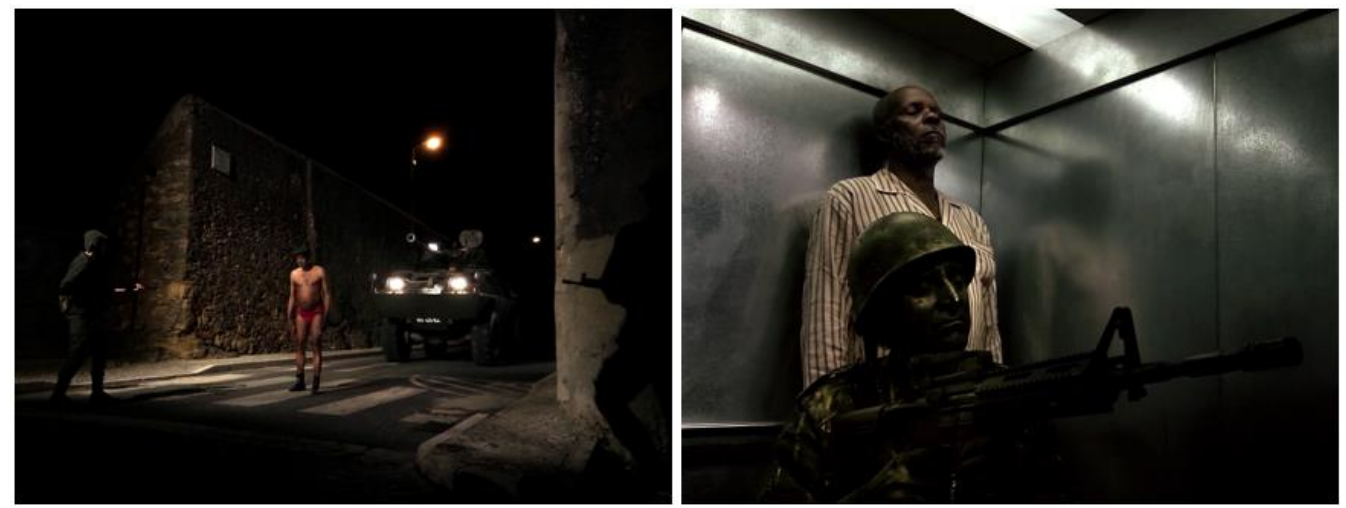

Imagens 5 e 6: Ventura em Cavalo Dinheiro| (C) OPTEC Sociedade Óptica Técnica.

Deparamo-nos com o choque de Ventura, suas mãos a tremer com uma intensidade visível. Esta sequência terá uma ressonância direta na cena em que Ventura entra num elevador e, ao lado de um soldado armado, assemelhando-se a uma estátua, revive momentos do conflito, ouvindo gritos, vozes e partes de um diálogo partido. Nessa composição que mescla memórias de um momento histórico e evidências do trauma vivido, passado e presente também se entrelaçam. "19 anos e 3 meses", repete Ventura, preso nesse tempo-espaço não cronológico. "19 anos e 3 meses": uma casa não construída, os filhos que não nasceram, um reencontro com a esposa que nunca foi possível. É na fresta entre luz e sombra, nesse entre-lugar da própria imagem, que a história se apresenta nos filmes.

\section{Corporeidades do Trauma}

A relação entre testemunho pessoal e histórico nos filmes é acompanhada pela imagem constante das mãos trêmulas de Ventura. A presença desse tremor ao longo dos filmes Cavalo Dinheiro e Vitalina Varela permite pensar o cinema de Pedro Costa não só enquanto processo de elaboração de uma memória histórica e traumática, mas, principalmente, como uma construção afetiva e uma corporeidade do trauma, que se inscreve ao largo da linguagem do testemunho. É preciso especificar, aqui, que a noção de trauma à qual fazemos referência se baseia na proposta de Anne Rutherford sobre a 
articulação do trauma no cinema. Para a autora, está claro que há vários tipos de trauma e diferentes graus de traumatização: “O termo 'trauma' engloba tanto as experiências 'limite' de sobrevivência quanto experiências que não necessariamente derivam de atrocidades ou situações extremas" (Rutherford 2013, 81). Nesse sentido, há experiências mais próximas de uma aniquilação física e uma desintegração psíquica e outras mais "cotidianas", que também são consideradas como parte da extensão das experiências do trauma. As mãos trêmulas de Ventura são, ainda, um ponto de tensão que coloca esses filmes num limiar ou lugar fronteiriço entre a realidade do trauma - a dizer, os sentidos da desterritorialização de sujeitos dos espaços coloniais em um contexto contemporâneo pós-colonial e suas consequências - e as operações materiais da própria forma como as imagens registram uma memória do trauma.

Essas mãos trêmulas catalisam, também, duas problematizações em torno da noção de trauma. A primeira diz respeito à forma como os filmes se colocam na fronteira entre a representação da experiência do trauma e a resistência a uma organização histórica e discursiva linear das origens desse trauma, instaurando assim uma sensorialidade e materialidade afetiva na imagem. Tratamos dessa posição fronteiriça a partir da análise da representação de corpos deslocados e sujeitos em crise, principalmente a partir do corpo doente e exausto de Ventura e do corpo em luto e em choque de Vitalina. A segunda busca articular as características inerentes à forma dos filmes no seu rigor formal, especialmente quanto ao uso do enquadramento e da temporalidade, que converge com um engajamento ético e político, sem uma aspiração redentora ou moralista. Nesses filmes, esse engajamento se torna possível a partir da distância que se estabelece, para usar o termo de Rancière (2012), que resiste a uma expressão simbólica, mas que aponta para uma contemplação inteligente, muito mais inquietante, e que nos impede de transformar a experiência da dor em um problema puramente estético.

Como, então, os filmes se valem do afeto e da distância para articular a experiência do trauma? Logo após a primeira sequência de Cavalo Dinheiro, em que Ventura aparece se aproximando lentamente da câmera estática, caminhando por uma espécie de corredor subterrâneo quase completamente escuro, há uma cena em que Ventura está numa cama de hospital e recebe uma visita de seus companheiros. Ali, a câmera está fixa, os personagens também, mas a mão de Ventura 
continua trêmula, irrompendo o caráter estático dessa imagem. Não sabemos ao certo o que acarretou a internação de Ventura, tampouco seu estado de saúde (cuja fragilidade somente é registrada pelas mãos trêmulas e pelo olhar perdido nessas cenas iniciais). O que se inscreve, nessa sequência, é um diálogo pouco linear entre os personagens, que antecipa uma narrativa enigmática, cujas temporalidades históricas se entrelaçam. Por exemplo, as alusões aos soldados das forças armadas, em referência, mais uma vez, ao legado da Revolução dos Cravos e a participação dos imigrantes nesse processo, se confundem à narração dos acidentes de trabalho e suas consequências no corpo e na vida dos trabalhadores.

Há, no entanto, duas falas nessa cena reveladoras da articulação estética e política de Cavalo Dinheiro, que posteriormente reverbera em Vitalina Varela. Um dos homens diz: "Ventura, não se esqueça do seu passaporte. Numa situação como esta, nunca se sabe..." (00:05:26 00:05:34). Em seguida, ele fala: "Lembra-se de nossos companheiros?" A câmera enquadra um deles em close-up e a fala continua: "Delgado. Datilógrafo. Ele tinha uma boa família. Uma boa casa em Zambujal. Uma noite, ele terminou seu jantar, colocou seus filhos na cama, esperou sua esposa adormecer, e, em seguida, queimou sua casa. Nunca mais abriu a boca novamente" (00:06:29 - 00:06:55). A referência ao passaporte já indica de que forma o filme irá retratar essas vidas deslocadas. Não há, nessa fala, qualquer explicação do motivo de levar consigo um passaporte, mas entende-se que esses corpos deslocados estão sujeitos a uma constante vigilância e a instâncias de controle.

Tanto em Cavalo Dinheiro quanto em Vitalina Varela torna-se visível o controle biopolítico desses corpos tornados dóceis, muitas vezes, pela experiência da desterritorialização. Assim se dá a articulação dos corpos diaspóricos e espaços pós-coloniais nesses dois filmes. Os personagens estão, na maior parte do tempo, em espaços de contenção e controle: hospitais, clínicas, escritórios de fábrica, igreja, quando não enquadrados em cenários escuros, enclausurados e claustrofóbicos como nos corredores e nas suas casas pequenas. A docilidade, como primeiro apontou Foucault, retomado por Agamben (2013), resultaria de uma "modernidade biológica", na qual o controle disciplinar seria alcançado por um novo biopoder, criador de corpos dóceis. Os corpos de Ventura e Vitalina, sua apreensão pela câmera, manifestam a "vida nua" desses sujeitos em um ponto de atravessamento do poder burocrático-jurídico-institucional e de um "modelo de poder 
biopolítico" (Agamben 2013, 138). É importante atentar que esses espaços se configuram como instituições de controle e vigilância (Foucault, 2014). Corredores e túneis estreitos, casas precárias, ruas sujas e mal iluminadas se revelam como espaços em ruínas, que indicam que eles se encontram às margens em todas as esferas da vida. O luto também é daqueles que se perderam na escuridão, como pondera o Padre.

É possível argumentar que o controle biopolítico dos corpos nos filmes é amparado pela forma como esses corpos se revelam atônitos frente ao trauma. O exemplo citado do companheiro que incendiou a casa, matando a família, e que depois perdeu a fala revela a dinâmica de um certo modo de silenciamento desses sujeitos. Como afirma Jill Bennett $(2005,3)$, já há um certo consenso de que o trauma é "classicamente definido como estando além do escopo da linguagem e da representação" e, portanto, uma arte sobre o trauma não adere necessariamente a uma lógica da representação. Do ponto de vista fílmico, emudecer esse personagem reforça a ideia de impossibilidade de representar a experiência do trauma e da crença de que "a arte pode apreender e transmitir uma experiência real" (Bennett 2005, 3), ou a experiência do real.

Pedro Costa nos coloca, então, diante de vestígios do trauma, da doença e do luto. Porém, ao invés de usar as formas clássicas do testemunho, seus personagens são colocados no impasse da burocratização e institucionalização da vida. A presença escultural de Vitalina em Cavalo Dinheiro, por exemplo, materializa esse impasse. Dentro do quadro escuro da tela, a luz incide sobre a face de Vitalina. Com olhar perdido voltado para o extracampo, ela narra sua chegada a Portugal. Conta da notícia da doença do marido, quando ainda estava em Cabo Verde. Conta do choque e da forma como embarcou. Ela narra em voz baixa: "Meu rosto estava todo desfigurado (...) Eu estava cega, não podia sentir nada. (...) Eu estava ardendo de febre" (00:20:15 - 00:20:55). Tudo foi sentido no corpo e essa somatização instaura nos corpos espaços de intensidade afetiva. Vitalina, em seguida, conta que chegou três dias depois do enterro do marido.

A esse testemunho fragmentado, junta-se a leitura sussurrada que Vitalina faz de documentos oficiais de embaixadas e cartórios, como as certidões de nascimento, de óbito e de casamento, sobrepondo as geografias de Portugal e Cabo Verde. Nessa sequência, Vitalina e Ventura estão no que parece ser um consultório médico, onde, em uma 
das paredes, uma tela branca emana uma luz incandescente. Vitalina veste um jaleco e continua a leitura das certidões. A câmera enquadra o rosto de Vitalina em close-up, que fica escurecido pela contraluz branca. O choro discreto de Vitalina ao final da leitura dos documentos é caracterizado apenas por uma lágrima que corre pelo rosto. Estamos diante de uma das características mais presentes e mais comentadas no cinema de Pedro Costa que é a "desdramatização" da performance de seus atores. A leitura dos documentos se impõe como um testemunho burocrático da vida de Vitalina, com uma potencialidade afetiva que se constitui na imagem e não na organização discursiva que especularia em torno das funções psíquicas da experiência do trauma. Há, portanto, uma reconfiguração da experiência sensível.

Se a personagem de Vitalina articula e atravessa diferentes geografias, a construção fragmentada do personagem de Ventura atravessa diversas temporalidades. Ventura sofre ao longo de todo o filme com os efeitos de um trauma, também indefinido, mas certamente articulado ao legado do colonialismo e às consequências da imigração ou diáspora. Além das mãos trêmulas, que ele associa à medicação que lhes dão, Ventura vaga desnorteado pelos espaços vazios do hospital, da fábrica, dos corredores subterrâneos, da cidade escura. Suas falas são elípticas e revelam não só sua dor física, mas momentos de alucinação. Refere-se ao seu tremor como uma doença dos nervos e em outro momento afirma: "Eu sei qual é a minha doença”. O tom fantasmagórico, como muitos críticos descrevem, coincide com as diversas referências à condição de estar vivo, como lhe diz Vitalina em um dos diálogos entre eles. O tema da vida e da morte, intensificado em Vitalina Varela, já se faz presente na condição do corpo doente de Ventura.

Numa das cenas que narra uma briga entre Ventura e outro companheiro, vemos Ventura deitado, agonizando depois de levar uma facada. Em outro momento, Ventura é capturado no meio do mato por soldados das forças armadas. Cavalo Dinheiro encena diversos momentos da vida de Ventura, confundindo as temporalidades desses eventos que estão no limite da morte. Como lhe diz um outro personagem, Ventura morreu mil mortes. Algumas análises do filme associam a fantasmagoria e o caráter alucinatório dos filmes às performances dos personagens e ao seu discurso confuso e fragmentado. A análise de Emma Fajgenbaum $(2019,155)$ propõe uma leitura dos corredores subterrâneos do filme relacionada esteticamente a El Manicomio (1812-1814), do pintor Francisco Goya, pensando 
nesses espaços como "câmaras de sua mente alucinada". É possível afirmar, no entanto, que, além do tratamento fílmico da natureza psíquica dos traumas, os filmes nos colocam num lugar de impossibilidade da compreensão da dor. Isto se dá, em grande parte, pelo rigor formal dos filmes.

Tanto Cavalo Dinheiro quanto Vitalina Varela ativam uma estética já presente nos filmes anteriores de Pedro Costa. Como Patrícia Brás argumenta,

Costa emprega o quadro e sua relação subsequente com o extracampo, o uso da desdramatização na performance de seus atores/personagens, a temporalidade distendida, a duração, intensificada pelo som, e a articulação repetitiva da montagem que interrompe o tempo linear e histórico. (Brás 2014, 11)

A autora propõe que os aspectos formais do cinema de Pedro Costa apontam para um gesto ético e político. Acrescentamos a esse argumento a ideia de que a organização formal sugere uma maneira de engajamento do espectador porque opera numa quebra com uma inteligibilidade simbólica e uma função interpretativa. Indo de encontro a uma linearidade discursiva e histórica, as imagens materializam afetos enquanto uma intensidade, a partir de um modo de distanciamento.

Por meio de um modelo de observação quase etnográfico dos sujeitos diaspóricos, que tem um caráter de compromisso com a comunidade que filma, os filmes se concentram nos personagens de Ventura e Vitalina e funcionam como uma espécie de "filme-retrato" (Tarrant 2013), que, de acordo com Paul Arthur (2003), privilegia a presença não-dramática de seus personagens, abstendo-se de compor uma biografia. Esses retratos, como acrescenta Vinicius Navarro (2012), conferem mais importância a cenas desprovidas da complexidade narrativa de grandes eventos para dar lugar a uma forma de exposição que se desenrola no presente. Retomando a definição de Arthur, Navarro acrescenta:.

Exposição, em outras palavras, tem precedência sobre o enredo. Por falta de uma articulação 'adequada', os filmes-retrato dependem da pose do/a retratado/a para produzir o sujeito/tema do filme. A câmera não documenta tanto a situação que existe antes do momento da filmagem, mas ajuda a criar a 
situação através da troca com o sujeito em performance. (Navarro 2012, 137, nossa tradução)

Essa forma de figuração se distingue de uma tipagem sócio-política, ou do que Jacques Aumont (1992) definiu como "rosto genérico", que aponta para uma representação de classe, como encontramos, por exemplo, nos rostos eisensteinianos. Segundo Ronald Bogue (2003, 78), estamos mais próximos, aqui, do rosto "intensivo" de Deleuze (em oposição ao rosto "reflexivo"), que "desterritorializa a face" e a distancia de suas funções mais convencionais, que incluem dar características ao indivíduo ou manifestar um papel social. No entanto, é importante ressaltar que essa desterritorialização das coordenadas espaço-temporais, características da imagem-afecção, não operam puramente no nível de uma estetização desses corpos. A esse tipo de composição, quase desprovida de movimento, Pedro Costa insere uma duração prolongada, colocando, em primeiro plano, o jogo entre a estaticidade da imagem e o tempo. Nuno Barradas Jorge comenta o aspecto temporal do cinema de Pedro Costa:

Essas representações de cabo-verdianos fazem parte de um retrato mais abrangente de personagens marginais. Compartilhando uma vitimização cultural e social comum, esses imigrantes também fazem parte dos heróis abjetos que constituem parte das margens sociais pós-coloniais e pósrevolucionárias. Pode-se facilmente tomar uma posição crítica a respeito das questões sociais retratadas. No entanto, o tom idiossincrático dos filmes de Costa apresenta uma natureza mais observacional, preocupada em problematizar a pobreza com uma lenta e contemplativa textura emocional, que traduz o deslocamento dos personagens numa forma individualista. (Jorge 2014,54 , nossa tradução)

Em sua lentidão, os filmes priorizam o desenrolar de eventos e não um encadeamento de ações. Um evento seria, no sentido proposto por Mary Ann Doane (2002, 140), “por sua natureza, aquilo que é inassimilável, que resiste significado, que, como o índice, serve primordialmente como uma garantia do real - algo está acontecendo" (nossa tradução). Doane afirma que, no cinema, o evento seria uma alternativa ao espetáculo (lugar do desejo e da fantasia), que suspende o ritmo narrativo e que está localizado dentro de uma estrutura, um limite também temporal. O evento, no entanto, abriga a contingência. 
Percebe-se, nas imagens dos dois filmes, uma abertura para o evento. Retomando a história de Vitalina onde Cavalo Dinheiro parou, Vitalina Varela expõe o corpo em luto e em choque de Vitalina ao chegar a Portugal. Como mencionamos acima, sua primeira fala é "cheguei atrasada”, porque não conseguiu chegar a tempo para enterrar o marido. O filme alterna entre uma construção narrativa através das falas dos conhecidos do marido que vêm vê-la, intercaladas com os monólogos de Vitalina, que conversa com o marido morto. Além de revelar sua tristeza e ressentimento, as falas também narram detalhes, como a data do casamento, a migração do marido, num tom quase burocrático, como nas leituras das certidões em Cavalo Dinheiro.

Os espaços quase completamente escuros do filme dificultam ainda mais a apreensão do pró-fílmico e deixam apenas focos de luz em alguns detalhes do quadro. Um desses vários momentos ocorre quando Vitalina está só, sentada numa pose quase estática, como que paralisada pelo choque. A câmera se detém na pose escultural de Vitalina, intensificada pela iluminação. Enquadrada num plano médio, ela parece nos encarar. Discretamente, uma lágrima escorre pelo rosto. Só a lágrima parece se mover nesse longo plano, até ela desviar o olhar para o extracampo. Como as mãos trêmulas de Ventura, que insistem em romper a estaticidade da mise-en-scène, a lágrima é o que Vitalina não contém. 


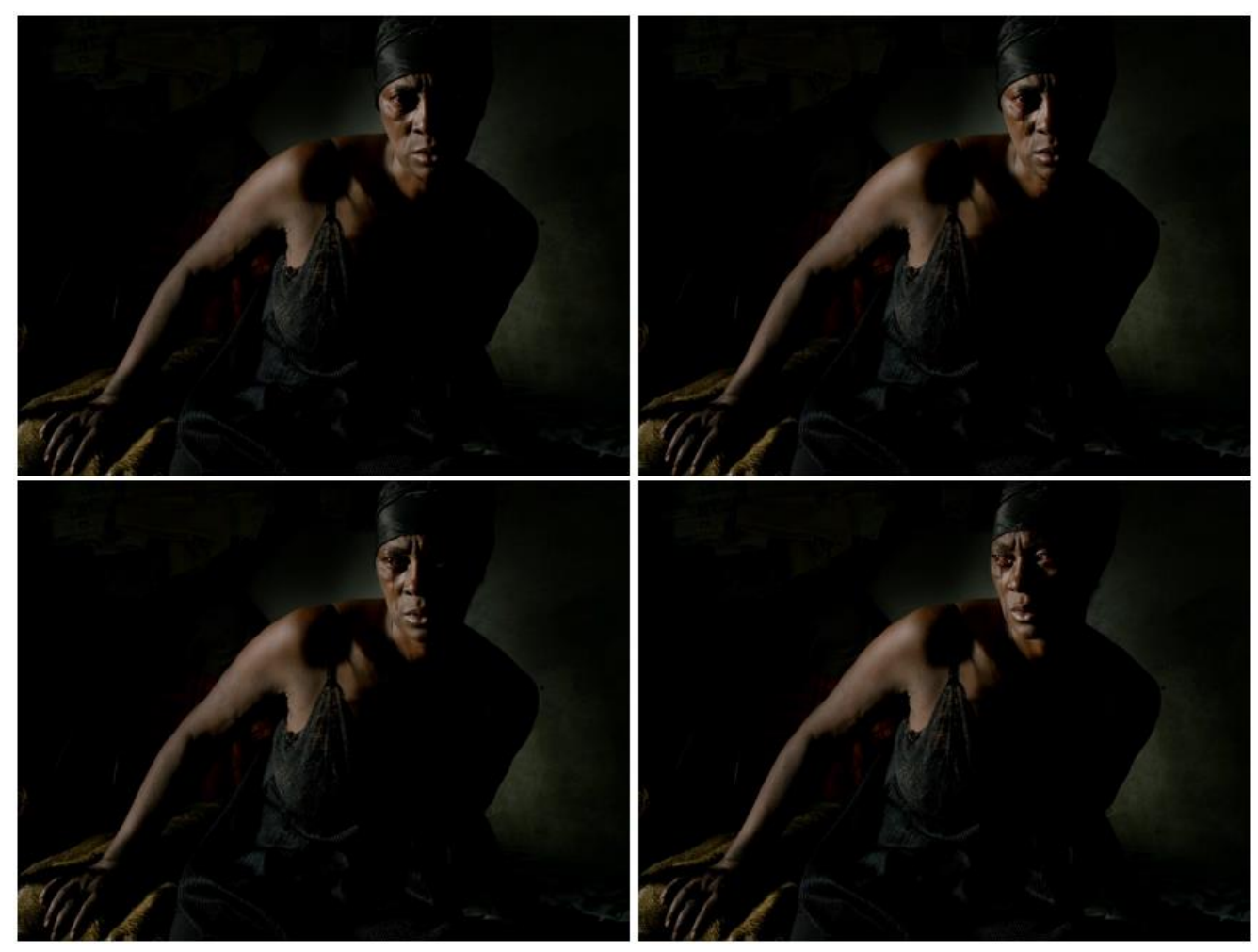

Imagens 7, 8, 9 e 10: Vitalina em Vitalina Varela|® OPTEC Sociedade Óptica Técnica.

É no pequeno detalhe que o filme apreende a forma de exteriorização do luto. A articulação temporal, que exige uma observação prolongada, e espacial, com o enquadramento, que não nos coloca a uma proximidade extrema a Vitalina, cria um distanciamento. Nós, espectadores, somos colocados num "lugar de mobilidade" (Mondzain 2009, 34, nossa tradução), e não presos ao conteúdo simbólico da narrativa. Nesses corpos e faces, os filmes apelam para um sentido fisionômico, que "aparece em sua completude somente dentro de uma abertura atenta e sensível à experiência pré-reflexiva" (Mazis 2016, 82, nossa tradução).

Essa operação de enquadramentos também surge nos planos tableau que não focalizam os rostos dos personagens, mas sim grupos de pessoas, que parecem emergir como tableaux-vivants, a partir dos quais articulam-se eventos à percepção do tempo. Algo ali acontece. Algo é sentido. Há espaço e distanciamento para contemplação. 

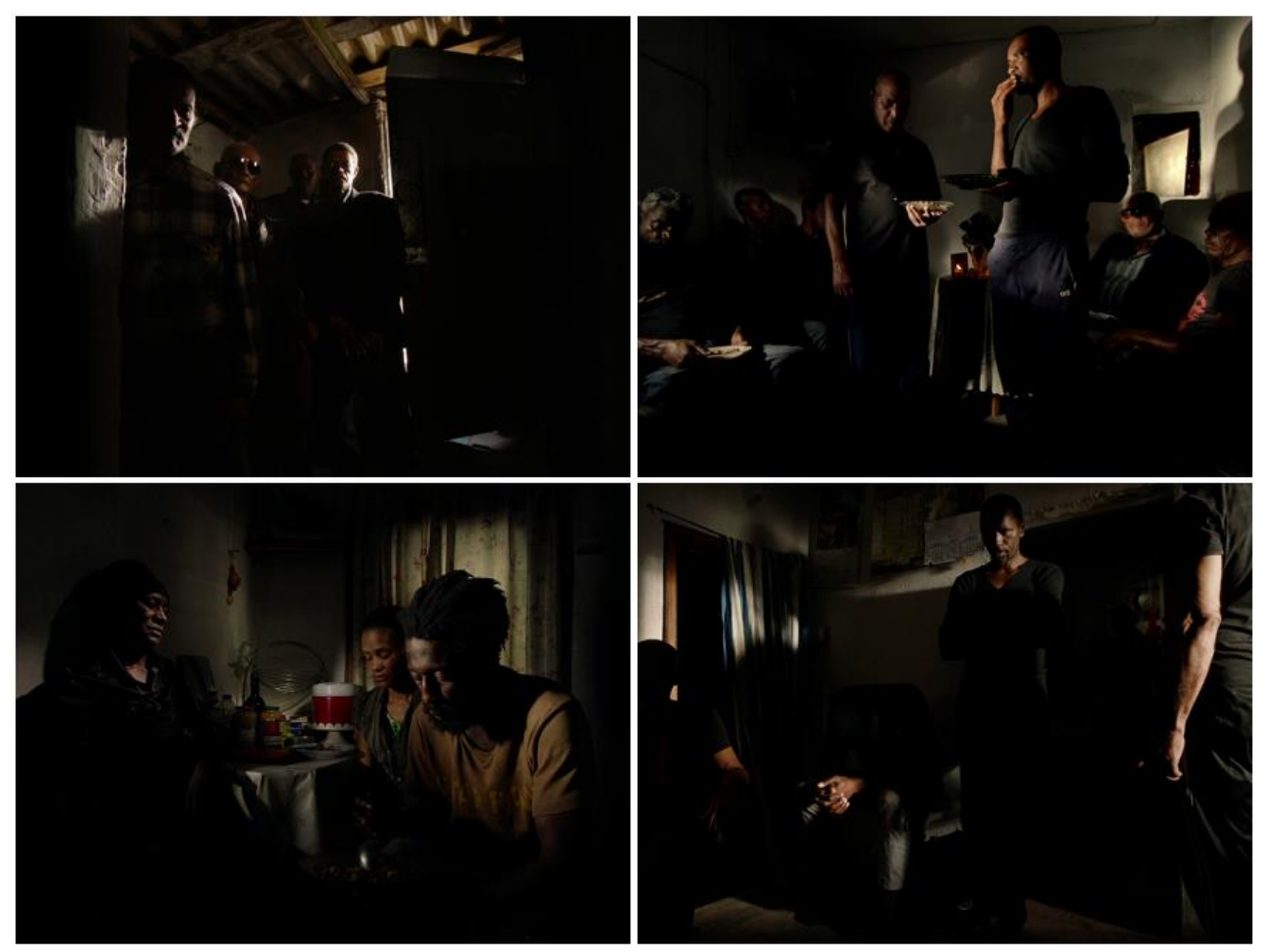

Imagens 11, 12, 13 e 14: Tableaux-vivants em Vitalina Varela | (c) OPTEC Sociedade Óptica Técnica.

Nessas várias imagens, os personagens, como um conjunto, se posicionam frente à câmera, com o olhar em direção ao observador, parados, quase imóveis, e, quase sempre, o movimento mínimo surge apenas de um ou dois personagens, como uma mão que leva um garfo à boca ou um olhar que muda de direção. São retratos coletivos desses sujeitos, que oferecem uma abertura para o evento e para a "profusão dos efeitos de realidade", materializados nessa abertura. ${ }^{2} \mathrm{O}$ filme nos coloca diante da dor do outro, para usar a famosa expressão de Susan Sontag (2003). No entanto, não estamos diante de imagens violentas, fabricadas para chocar. Como coloca Rancière (2012, 160-161), referindo-se a Juventude em Marcha (2006), “com Ventura, não é o caso de registrar o testemunho de uma vida difícil, com o inconveniente de descobrir como levá-lo a partilhar isso. Trata-se de enfrentar o que é impossível de compartilhar, a fissura que separou o indivíduo de si mesmo". Diante desses personagens esculturais, por vezes imóveis e

${ }^{2}$ A expressão é usada por Jacques Aumont $(2004,31)$ para comentar as vistas dos irmãos Lumière.

aniki Materialidades no Cinema Português | Materiality in Portuguese Cinema 
atônicos, não estamos, nem nós, espectadores, nem eles, inertes frente à história. E apesar de Ventura afirmar que não consegue sentir seu braço ou que seus dedos estão paralisados por causa do choque, o movimento emerge e rompe a imobilidade.

\section{Considerações finais}

Com o intuito de pensar as operações materiais que compõem Cavalo Dinheiro e Vitalina Varela, este artigo propôs uma reflexão sobre a inscrição da história e a corporeidade do trauma nos filmes. Partimos da própria ideia de materialidade como prisma para a análise, levando em conta a ruptura radical no processo e na forma de filmar, adotadas por Pedro Costa a partir do filme No Quarto da Vanda, em que o gesto de abandono do aparato pesado de $35 \mathrm{~mm}$ motivou um novo método.

A meticulosa e lenta observação dos personagens, focada em Ventura e Vitalina, longe de compor uma descrição ou tipagem social e política da realidade dos imigrantes ou descendentes de imigrantes caboverdianos em Portugal, nos coloca diante da fissura, para usar o termo de Rancière, e do incompartilhável. As formas de inscrição de fatos e personagens históricos não apelam para o didatismo. Ao contrário, enfatizam as vidas dos que perderam o tempo, como Vitalina, dos que chegaram atrasados. No registro da imobilidade operado pela performance dos personagens, pela câmera, pela duração, os filmes desvelam histórias individuais daqueles cuja vida foi atrasada, silenciada, roubada. Nas fronteiras da história e nos entre-lugares (Bhabha 1998) da pós-colonialidade, esses sujeitos diaspóricos compartilham a experiência histórica do exílio e da opressão, trazendo em seus corpos as marcas da doença, do trauma, do colonialismo, do racismo.

Em seus dois filmes mais recentes, Pedro Costa demonstra o aprimoramento de uma forma de filmar que toma como potência afetiva a materialidade fílmica. Cavalo Dinheiro e Vitalina Varela nos levam a questionar o que nos move diante da dor dos outros. Seguindo Rancière, afirmamos que a formalidade de Pedro Costa nos interpela a uma contemplação inteligente, porque não nos aprisiona a uma compreensão didática do testemunho da experiência traumática. Seus filmes também não nos colocam numa posição de empatia engendrada pela identificação com os personagens. A corporeidade dos afetos que a forma das imagens produz nos coloca diante de uma inquietação ética e 
política, motivada por uma sensorialidade que leva a uma forma de pensar. Trata-se, portanto, citando Jill Bennett $(2005,15)$, de uma ética "ativada e revigorada pela capacidade de transformação".

\section{Referências}

Agamben, Giorgio. 2013. "Introduction to Homo Sacer. Sovereign Power and Bare Life". Em Biopolitics: A Reader, editado por Timothy Campbell e Adam Stize, 134-144. Durham e Londres: Duke University Press.

Arendt, Hannah. 2007. A Condição Humana. Tradução de Roberto Raposo. Rio de Janeiro: Forense Universitária.

Arthur, Paul. 2003. "No Longer Absolute: Portraiture in American Avant-Garde and Documentary Films of the Sixties". Em Rites of Realism: Essays on Corporeal Cinema, editado por Ivone Margulis, 93-118. Durham e Londres: Duke University Press.

Aumont, Jacques. 1992. Du Visage au Cinéma. Paris: Editions de L'Etoile/Cahiers du Cinéma. . 2004. O Olho Interminável: Cinema e Pintura. Tradução de Eloisa Araújo Ribeiro. São Paulo: Cosac Naify.

Benjamin, Walter. 1994. "Sobre o Conceito de História”. Em Magia e Técnica, Arte e Política. Obras escolhidas I, tradução de Sérgio Paulo Rouanet, 222-232. São Paulo: Brasiliense.

Bennett, Jill. 2005. Emphatic Vision: Affect, Trauma, and Contemporary Art. Bloomington: Stanford University Press.

Bhabha, Homi. 1998. O Local da Cultura, tradução de Myriam Ávila, Eliana Lourenço de Lima Reis, Gláucia Renate Gonçalves. Belo Horizonte: Editora da UFMG.

. 2003. "Democracy De-realized." Diogenes, 50(1): 27-35. https://doi.org/10.1177/039219210305000104

. 2014. “The Right to Narrate". Harvard Design Magazine 38. http://www.harvarddesignmagazine.org/issues/38/the-right-tonarrate (último acesso a 10 dezembro 2020).

Bogue, Ronald. 2003. Deleuze on Cinema. Nova Iorque e Londres: Routledge. 
Brás, Patrícia. 2014. The Political Gesture in Pedro Costa's Films. Tese de doutorado. Birkbeck, University of London.

Didi-Huberman, Georges. 2017. "Povos expostos, povos figurantes". Revista Vista - Políticas do Olhar 1: 16-31. https://doi.org/10.21814/vista.2963

Doane, Mary Ann. 2002. The Emergence of Cinematic Time: Modernity, Contingency and the Archive. Cambridge: Harvard University Press.

Duarte, Daniel Ribeiro. 2010. "Para que tudo seja diferente". Em $O$ Cinema de Pedro Costa, organizado por Daniel Ribeiro Duarte, 1115. Centro Cultural Banco do Brasil/Associação Filmes de Quintal.

https://edisciplinas.usp.br/pluginfile.php/4693546/mod_resour ce/content/1/Catalogo $\% 20$ Pedro $\% 20$ Costa $\% 2$ C $\% 20$ CCBB $\% 20 \% 2$ 82010\%29.pdf (último acesso a 10 dezembro 2020).

Fajgenbaum, Emma. 2019. "Cinema as Disquiet: The Ghostly Realism of Pedro Costa”. New LeftReview 116: 137-159.

Foucault, Michel. 2014.Vigiar e Punir: Nascimento da Prisão. Tradução de Raquel Ramalhete. Petrópolis: Vozes.

Jorge, Nuno Barradas. 2014. "Thinking of Portugal, Looking at Cape Verde: Notes on Representation of Immigrants in the Films of Pedro Costa". Em Migration in Lusophone Cinema, editado por Cacilda Rêgo e Marcus Brasileiro, 41-57. Nova Iorque: Palgrave Macmillan.

. 2020. ReFocus: The Films of Pedro Costa. Producing and Consuming Contemporary Art Cinema. Edimburgo: Edinburgh University Press.

Mazis, Glen A. 2016. Merleau-Ponty and the Face of the World: Silence, Ethics, Imagination and Poetic Ontology. Nova York: SUNY Press.

Mondzain, Marie-José. 2009. “Can Images Kill?”. Critical Inquiry 36: 2051. https://doi.org/10.1086/606121

Navarro, Vinicius. 2012. "Nonfictional Performance from Portrait Films to the Internet”. Cinema Journal 51(3): 136-141.

Oliveira Jr, Luiz Carlos. 2016. "Cavalo Dinheiro e a Arte do Retrato". Revista $\quad$ Cinética. 25 janeiro 2016. http://revistacinetica.com.br/home/cavalo-dinheiro-e-a-artedo-retrato/ (último acesso a 10 dezembro 2020). 
Rancière, Jacques. 2012. As Distâncias do Cinema. Tradução de Estela dos Santos Abreu. Rio de Janeiro: Contraponto. . 2020. "Dos Ojos en la Noche: Jacques Rancière sobre Vitalina Varela" Revista Oropel. 20 outubro 2020. http://revistaoropel.cl/index.php/2020/10/20/dos-ojos-en-lanoche-jacques-ranciere-sobre-vitalinavarela/?fbclid=IwAR06uoqySEq9S_ObcVWx_IKIFdFYkzbVfrwGz2BmyDcMRfrSAWGq8eaOq4

Rutherford, Anne. 2013. "Film, Trauma and the Enunciative Present". Em Traumatic Affect, editado por Meera Atkinson e Michael Richardson, 80-128. Cambridge: Cambridge Scholars Publishing.

Sontag, Susan. 2003. Diante da Dor dos Outros. Tradução de Rubens Figueiredo. São Paulo: Companhia das Letras.

Tarrant, Patrick. 2013. "Montage in the Portrait Film: Where Does the Hidden Time Lie?". Alphaville: Journal of Film and Screen Media 5: $1-15$.

\section{Filmografia}

Cavalo Dinheiro. [Longa-metragem, DCP]. Dir. Pedro Costa. OPTEC, Portugal, 2014. 103min.

Juventude em Marcha. [Longa-metragem, DCP]. Dir. Pedro Costa. Francisco Villa-Lobos, Ventura Film, Portugal, 2006. 115min.

No Quarto da Vanda. [Longa-metragem, DCP]. Dir. Pedro Costa. Francisco Villa-Lobos, Contracosta Produções, Portugal, 2000. 170min.

Ossos. [Longa-metragem, 35mm]. Dir. Pedro Costa. Paulo Branco, Madragoa Filmes, Portugal, 1997. 94min.

Vitalina Varela. [Longa metragem, DCP]. Dir. Pedro Costa. OPTEC/CA, Fundação Calouste Gulbenkian, Câmara Municipal de Lisboa, Portugal, 2019. 124min. 


\title{
Restoring history, materializing the trauma: Observations on the migrant bodies in Pedro Costa's Cavalo Dinheiro (2014) and Vitalina Varela (2019)
}

\begin{abstract}
This essay proposes a reflection on the way in which Cavalo Dinheiro/ Horse Money (2014) and Vitalina Varela (2019), by Portuguese director Pedro Costa, restore the right to narrate and materialize the effects of the trauma related to migration and colonialism, from the analysis of the inscription of diasporic bodies and subjectivities in the contemporary postcolonial space, more specifically within the context of the representation of Cape Verdean immigrants and their descendants in Portugal. The notion of materiality is the prism through which this analysis is devised, both in the sense of the materiality of the cinema apparatus employed by the filmmaker, and in the sense of the materiality of the very image and its formal operations in the construction of the experience of history and of trauma. The essay contends that these formal operations, especially the use of (historic and filmic) temporality and the framing that creates a distance, reveal not only a singular aesthetics, but also a political and ethical engagement in Pedro Costa's cinema.
\end{abstract}

KEYW ORDS Pedro Costa; trauma; body; materiality; history; affect.

Recebido a 15-12-2020. Aceite para publicação a 17-04-2021. 